\title{
Effects of a 24-week Exercise Programme on Normal Adults and Patients with Previous Myocardial Infarction*
}

\author{
P. A. RECHNITZER, M.D., F.R.C.P.C., M.R.C.P.ED.; M. S. YUHASZ, PH.D. ; A. PAIVIO, PH.D. \\ H. A. PICKARD, M.D., F.R.C.P.C. ; N. LEFCOE, M.D., F.R.C.P.C.
}

Brit. med. F., 1967, 1, 734-735

Several studies have suggested a relation between coronary artery disease and physical exercise. Animal experiments have failed to show a clear relation between the development of dietinduced atherosclerosis and physical activity. Kobernick et al. (1957) showed that rabbits on an atherogenic diet developed less atherosclerosis after 13 weeks of exercise on a rotating drum than a non-exercised group. Brainard (1959) failed to confirm these results. Evidence for a positive relation between physical activity and the development of coronary collateral circulation in both animals and man is somewhat more convincing (Eckstein, 1957 ; Stevenson et al., 1964). A gradual increase in physical activity is an important part of the rehabilitation of postinfarction patients, and they are now encouraged to resume their former activities. In a previous report the effects of a graduated exercise programme on a group of four patients with previous myocardial infarction were described (Rechnitzer et al., 1965). The present study surveys in greater detail some of the changes which occurred in four groups of men after a 24-week exercise programme.

\section{Method}

Group 1 (exercising cardiacs) consisted of eight male patients with a well-documented history and electrocardiographic findings of previous myocardial infarction (see Table I). The average age was 45 years and the duration since the infarction varied from six months to four years, averaging one and a half years. Group 2 (cardiac controls) included eight patients with previous myocardial infarction who met weekly for a recreational swim. The average age was 45 years and the duration since infarction varied from one and a half to nine years, averaging three years and three months. None of the cardiac subjects had cardiac enlargement or failure. One subject in group 2 had frequent ventricular premature beats and two subjects in group 2 had angina on effort. Group 3 (normal exercisers) consisted of eight sedentary men without known heart disease, who took part in a similar exercise programme. The average age was 38 years. Group 4 (sedentary controls) was composed of eight men, previously sedentary, who continued their sedentary habits. Their mean age was 41 years. Two subjects in group 1 and four in group 2 were anticoagulated. Smoking and diet were not controlled.

At the beginning and conclusion of the study all subjects had a physical examination, with chest radiograph, resting electrocardiogram, haemoglobin estimation, sedimentation rate, white and differential blood count, measurement of serum protein electrophoresis, serum cholesterol (Pearson et al., 1953), triglycerides (Van Handel and Zilversmit, 1964), and free fatty acids (Trout et al., 1960). Pulmonary function tests included forced vital capacity, first second forced expiratory volume, first second divided by forced vital capacity, and maximum mid-expiratory flow rate. Subcutaneous fat was measured at six selected sites with the Harpenden calliper. Muscular endurance was assessed with the five-minute muscular endurance test (Rechnitzer et al., 1965). This consisted of a battery of six individual test items (push-ups, sit-ups, chest raise, double leg raise, side leg raise, and sitting tucks) performed in a fixed

TaBle I.-Classification of Groups

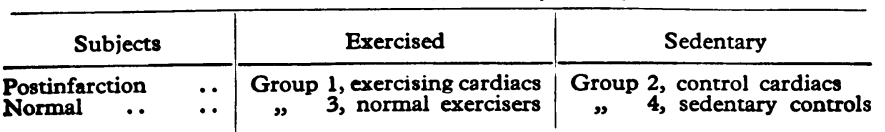

sequence within a set time limit. The two normal groups were tested on these items in the second week of the exercise programme. The testing was delayed until the third week for the cardiac exercise group. The cardiac controls did not undergo this test. Changes in mood were assessed by means of a series of psychological tests which included the Cattell 16 personality factor questionary, the Bendig manifest anxiety scale, a semantic differential inventory, and the Cattell motivation analysis test. In addition, an interview was carried out with the wives of the cardiac subjects during the sixth week of the programme. Detailed results of the psychological assessment will be reported separately (McPherson et al., 1967) and only findings in general are included here.

\section{Exercise Programme}

Subjects in the exercise groups met, with an instructor, two evenings a week for 24 weeks. A physician was present at each of the sessions. The nature, principles, sequence, and form of the exercise session were described in a previous study (Rechnitzer et al., 1965). At the beginning of the fifth week the subjects began performing mild exercises daily at home. In addition they began a daily recreational walk of 1 mile $(1,600$ metres) which was gradually increased to 2 miles (3,200 metres) by the end of the study. The cardiac control group met once weekly with an instructor and engaged in a leisurely recreational swim lasting approximately 30 minutes. This group was used to control group-therapy effect on the psychological assessment. The normal exercisers met twice weekly, the exercise session being very similar in nature to those of the cardiac exercisers except for the earlier increase in intensity of the work-outs. At the completion of the study the intensity and duration of the exercise sessions were the same in normal as in cardiac subjects. In the tenth week the cardiac and normal exercisers met together on two occasions, and the cardiac subjects had no difficulty in keeping up with the controls.

\section{Results}

At the completion of the study the exercising subjects were able to perform a 30-minute session of vigorous exercises followed by interval running of 220 yards ( 200 metres) repeated six times. The cardiac exercisers and controls were apprehensive at the beginning but gradually gained confidence in their ability to take part in the programme. One in the cardiac control group suffered a myocardial infarction during the period of the study. Hospitalization for three weeks was followed by a convalescence of an additional three weeks at home. He then rejouned his group in the weekly recreational swim for the remainder of the 24-week period. The subject in the cardiac control group with frequent ventricular premature beats continued to have them at the conclusion of the study. The subject who suffered an acute myocardial infarction during the project showed characteristic electrocardiographic changes. There were no changes in the chest radiographs.

The blood data and pulmonary function tests were analysed by an analysis of variance and there were no significant changes between either cardiacs and normal subjects or between exercising and sedentary subjects. There was an increase in serum cholesterol $(\mathrm{F}=8.988, \mathrm{P}<0.01)$ in all groups at the conclusion of the study.

- Departments of Medicine and Physical Education, University of Western Ontario, London. Ontario, Canada. 
Subcutaneous Fat.-The total fat thickness of each group before and after the exercise programme is presented in Table II. Both exercise groups (cardiacs and normals) decreased in body fat $(F=14.74, P<0.01)$ at the completion of the programme, whereas non-exercisers showed a slight increase. The high initial value in the normal exercisers was due to the presence of two men who were very obese.

Muscular Endurance.-Change in performance in the six items of the five-minute muscular endurance test was analysed with the $t$ test. The cardiac exercisers showed significant improvement $(P<0.01)$ in each item in the test, the normal exercisers showed significant improvement on two items, and the sedentary controls showed no improvement.

Psychological Changes.-The cardiac exercisers and cardiac controls experienced significant subjective improvement in mood at the end of the programme. Both cardiac groups felt more confident and less anxious, and were able to enjoy their work and leisure more. The normal exercisers and sedentary controls showed little change. These subjective changes were reflected in the favourable trends occurring in Bendig's manifest anxiety scale and the semantic differential inventory. The interview with the wives of the cardiac exercisers and cardiac controls revealed that they had observed the same kind of mood changes as the subjects themselves had experienced since the beginning of the study. A semantic differential test given before and after a single exercise session early and late in the programme revealed little change in mood in the normal exercisers. Cardiac exercisers and cardiac controls showed a similar degree of mood elevation after a single exercise session or recreational swim during the 22 nd week of the study.

TABLE II.-Subcutaneous Fat Thickness in $\mathrm{mm}$.

\begin{tabular}{c|c|c|c}
\hline Group & Before Study & After Study & Difference \\
\cline { 2 - 3 } 1 & $105 \cdot 4$ & $89 \cdot 8$ & $-15 \cdot 6$ \\
2 & 118 & $122 \cdot 2$ & $+4 \cdot 2$ \\
3 & 167.9 & $154 \cdot 9$ & -13.0 \\
4 & 136.1 & 146.4 & +10.3 \\
\hline
\end{tabular}

\section{Discussion}

The exercise programme resulted in significant changes in all groups. The cardiac and normal exercisers showed significant reduction in subcutaneous body fat. The cardiac and sedentary control groups showed no change. Improvement in muscular endurance was more pronounced in the cardiac exercisers than in the normal exercising subjects. This was probably due to a stronger motivation among the cardiac subjects. The favourable psychological changes were not due entirely to the exercise itself, as the control cardiac subjects showed very similar mood changes.

Previous reports on the effects of exercise on serum cholesterol levels have been conflicting. In some studies where exercise was said to have resulted in a lowering of serum cholesterol there was little or no information on diet, and some subjects reported losing weight (Chailley-Bert et al., 1955 ; Golding, 1961). It is difficult to know whether the lowered serum cholesterol was due to the exercise, to loss of weight, or to changes in the composition of the diet. The increase in serum cholesterol in this investigation was not related to exercise, as it occurred in all groups, nor to weight gain, as it occurred in the exercising groups which lost weight during the study.

Most available data on serum triglyceride levels suggest a relation between raised levels and the development of ischaemic heart disease (Albrink et al., 1961). Difference of opinion exists whether knowledge of serum triglyceride level provides any more useful information than knowledge of serum cholesterol alone (Carlson, 1960). Holloszy et al. (1964) found a significant reduction in serum triglyceride levels in middle-aged men after an endurance training programme. This fall in serum triglyceride was an acute change occurring within a few hours of the work-out and lasting approximately 48 hours. The absence of change in triglyceride levels in our subjects could have been due to the interval of four days between the last exercise session and the collection of blood. That this explanation is unlikely, however, is suggested by a subsequent study (Rechnitzer et al., 1967) in which the acute effects of exercise on serum lipids were measured in postinfarct and normal subjects. There was no significant reduction in serum triglycerides in either group. It is also possible that the intensity of the exercise session in the present study was not sufficient to produce the reported lipid change.

The exercise programme did not seem to produce any significant effect on any of the ventilatory measurements. It has been well established that ventilatory function may deteriorate in any group of individuals over a winter season, presumably due to viral respiratory tract infections. The present study, including initial testing in the autumn and final testing in the spring, may have such a bias, thus adversely affecting any improvement due to exercise. Repeat studies the following autumn, after a summer presumably free of respiratory tract infection, would be of interest. In a pilot study the previous winter (Rechnitzer et al., 1965) the four subjects showed a mean significant improvement in the ventilatory measurements as the result of slight improvement in two of the individuals and a markẹd improvement in one with slight deterioration in the fourth. The present study, using larger numbers, does not support these preliminary findings.

No conclusions can be drawn regarding whether such an exercise programme had any effect on coronary collateral circulation, atherogenesis, or prognosis in human subjects with previous myocardial infarction. It can be stated, however, that the capacity for work in a small selected group of patients with previous myocardial infarction was greatly improved. Dramatic changes in mood also occurred as a result of such a programme. These may have been primarily due to a group-therapy effect rather than to exercise, as they occurred in both the exercising and the control cardiac subjects.

\section{Summary}

Eight men with previous myocardial infarction were exercised over a 24-week period and compared with groups of normal men who exercised, normal men who remained sedentary, and cardiac subjects who met together once a week but remained sedentary.

The exercising cardiac subjects showed loss of subcutaneous fat, increased muscular endurance, and very favourable changes in mood. The sedentary cardiac subjects showed a similar change of mood, while the normal exercising men showed diminution of subcutaneous fat and increase in muscular endurance.

We wish to thank Miss Edna Whyte for secretarial assistance and Mr. Mackie Smith and Miss Helen O'Malley for technical help.

\section{REFERENCES}

Albrink, M. J., Meigs, J. W., and Man, E. B. (1961). Amer. f. Med., 31, 4

Brainard, J. B. (1959), Proc. Soc. exp. Biol. (N.Y.), 100, 244.

Carlson, L A. (1960). Acta med. scand., 167, 399.

Chailley-Bert, Labignette, P., and Fabre-Chevalier (1955). Presse méd., 63,415 .

Eckstein, R. W. (1957). Circulat. Res., 5, 230

Golding, L. (1961). Res. Quart. Amer. Ass. Hith phys. Educ., 32, 499. Holloszy, J. O., Skinner, J. S., Toro, G., and Cureton, T. K. (1964). Amer. F. Cardiol., 14, 753.

Kobernick, S. D., Niwayama, G., and Zuchlewski, A. C. (1957). Proc. Soc. exp. Biol. (N.Y.), 96, 623.

McPherson, B., Paivio, A., Yuhasz, M. S., Lefcoe, N., Pickard, H. A., and Rechnitzer, P. A.'(1967). Amer. $\mathscr{\xi}$. Sports Med. In press.

Pearson, S., Stern, S., and McGavack, T. H. (1953). (Modified by Lab. of Hygiene, Dept. of National Health and Welfare, Manual of Clin. Chem. CH-2, 1959.)

Rechnitzer, P. A., Yuhasz, M. S., Paivio, A. U., Lefcoe, N., and Pickard, H. A. (1967). In press.

Pickard, H. A., and Lefcoe, N. M. (1965). Canad. med. Ass. F., 92, 858 .

Stevenson, J. A. F., Feleki, V., Rechnitzer, P., and Beaton, J. R. (1964). Circulat. Res., 15, 265.

Trout, D. L., Estes, E. H., and Friedberg, S. J. (1960). F. Lipid Res., $1,199$.

Van Handel, E., and Zilversmit, D. B. (1957). F. Lab. clin. Med., 50, 152. (Modified by S. N. Jagannathan, Canad. F. Biochem., 1964, 42, 566.) 